\title{
МЕДИАТИВНЫЕ ТЕХНОЛОГИИ В РАННЕМ И НЕПОСРЕДСТВЕННОМ ПРЕДУПРЕЖДЕНИИ ПРЕСТУПНОГО ПОВЕДЕНИЯ ШКОЛЬНИКОВ
}

\author{
Т. М. Судакова, С. А. Корягина \\ Байкальский государственный университет, г. Иркутск, Российская Федерация
}

Информация о статье

Дата поступления

9 июня 2017 г.

Дата принятия к печати 29 июня 2017 г.

Дата онлайн-размещения 15 сентября 2017 г.

\section{Ключевые слова}

Школьная медиация; ранняя криминологическая профрилактика; непосредственное предупреждение преступности несовершеннолетних; преступления несовершеннолетних

\begin{abstract}
Аннотация
Медиативные технологии сегодня апробированы во многих сферах нашей жизнедеятельности и признаны достаточно эффективными. Целесообразность их повсеместного внедрения в программы оздоровления социальных условий на уровне механизмов раннего и вторичного предупреждения преступного поведения школьников активно обсуждается в науке. Насколько эфффективна эта относительно новая профилактическая процедура и обладает ли она позитивным антикриминогенным потенциалом - вопрос, требующий дальнейшего осмысления. Теоретическая и прикладная функции школьной медиации требуют криминологического осмысления и определения ее места в механизме ранней профилактики преступного поведения несовершеннолетних. Целесообразность применения восстановительных медиативных процедур в школе в отношении несовершеннолетних учащихся, совершивших определенные категории и виды преступлений, ставит вопрос об актуальности рассмотрения школьной медиации как имманентного элемента вторичной, или непосредственной, профилактики преступного поведения и ее антикриминогенных свойствах. Блокирование или нейтрализация криминогенно значимых факторов применением конструктивного подхода к разрешению школьного конфликта, предотвращение его эскалации - плоскость в том числе криминологических исследований медиативных технологий в школе.
\end{abstract}

\section{MEDIATION TECHNOLOGIES IN EARLY AND DIRECT PREVENTION OF CRIMINAL BEHAVIOUR OF SCHOOLCHILDREN}

Tatyana M. Sudakova, Svetlana A. Koryagina

Baikal State University, Irkutsk, Russian Federation

\author{
Article info \\ Received \\ June 9, 2017 \\ Accepted \\ June 29, 2017 \\ Available online \\ September 15, 2017

\section{Keywords} \\ School mediation; early \\ criminological prevention; \\ direct prevention of juvenile \\ delinquency; juvenile crime
}

\begin{abstract}
Mediation technologies are tested in many spheres of our life and are considered rather effective. The issue whether it is reasonable to widely implement them in programs of social environment improvement at the level of the mechanisms of early and secondary prevention of criminal behavior in schools is discussed by scholars. Still there are questions to be considered: what extent is this relatively new procedure efficient to, and does it have the positive potential to prevent crime? Theoretical and applied functions of school mediation demand criminological understanding and the role of school mediation in the mechanism of the early prevention of criminal behavior of minors is to be determined. As soon as it seems feasible to apply restorative mediation procedures to minor schoolchildren who have committed certain categories and types of crimes, questions arise whether it is relevant to regard school mediation as an inherent part of the secondary or direct prevention of criminal behavior and what anti-criminogenic properties school mediation has? Blocking or neutralizing a criminogenic need by means of the constructive approach to resolving a school conflict and, thus, preventing its escalation is a sphere criminological research of school mediation technologies.
\end{abstract}


В современных условиях острота проблемы противодействия преступному поведению несовершеннолетних не снижается, несмотря на его относительно благополучные среднестатистические официальные тенденции. Преступность несовершеннолетних, как известно, в значительной мере дублирует тенденции взрослой преступности, имея при этом свою специфику. Даже краткое обобщение данных региональной статистики правоохранительных органов позволяет говорить о пролонгации тех тенденций, которые приобрели устойчивый характер в течение последнего десятилетия. Официальная статистика отражает не только сокращение объема преступности несовершеннолетних в последнее десятилетие, но и снижение степени ее общественной опасности. Структурные особенности зарегистрированных преступлений, совершенных несовершеннолетними, по степени их тяжести свидетельствуют о существенном преобладании преступлений средней тяжести. Удельный вес последних в 2016 г. увеличился в 1,2 раза по сравнению с базовым 2008 годом (табл. 1). Таким образом, в 2016 г. подростками совершено каждое второе преступление средней тяжести, как и каждое пятое преступление небольшой тяжести. Тяжкая преступность не превышает и четверти всех регистрируемых преступлений, составляя в последнее пятилетие среднестатистически немногим более 23 \% и ежегодно сокращаясь. В течение последнего десятилетия эта тенденция достаточно устойчива и приобрела признаки закономерности. Она характерна для всей преступности как в общероссийском масштабе, так и в региональном срезе.

Структурные особенности преступности несовершеннолетних по видам зарегистрированных преступлений не отражают также существенной специфики в сравнении с общероссийскими тенденциями и показывают преобладание преступлений против собственности, самыми распространенными среди которых являются хищения (табл. 2).

\section{Структурные особенности преступного поведения несовершеннолетних} в ИО по степени тяжести совершенных преступлений (по данным официальной статистики правоохранительных органов за 2008-2016 гг., \%)*

\begin{tabular}{|l|r|r|r|r|r|r|r|r|r|}
\hline Категория преступлений & \multicolumn{1}{c|}{2008} & \multicolumn{1}{c|}{2009} & \multicolumn{1}{c|}{2010} & 2011 & 2012 & 2013 & 2014 & 2015 & 2016 \\
\hline Особо тяжкие & 4,04 & 4,2 & 4,4 & 3,3 & 5,0 & 6,0 & 2,7 & 2,4 & 2,3 \\
\hline Тяжкие & 31,04 & 29,1 & 28,6 & 27,5 & 17,1 & 16,9 & 21,8 & 21,0 & 21,0 \\
\hline Средней тяжести & 48,70 & 50,5 & 51,7 & 55,8 & 56,2 & 56,0 & 56,7 & 56,8 & 55,3 \\
\hline Небольшой тяжести & 16,10 & 16,1 & 15,3 & 13,3 & 13,4 & 13,7 & 18,8 & 19,0 & 19,1 \\
\hline
\end{tabular}

* Составлена по данным ГИАЦ УВД по Иркутской области.

Таблица 2

Структура наиболее распространенных преступлений, совершаемых несовершеннолетними в ИО, по видам зарегистрированных преступлений, \%*

\begin{tabular}{|c|c|c|c|c|c|c|c|c|c|}
\hline Вид преступления & 2008 & 2009 & 2010 & 2011 & 2012 & 2013 & 2014 & 2015 & 2016 \\
\hline Убийство & 1,30 & 1,40 & 1,2 & 0,80 & 1,8 & 0,5 & 1,0 & 1,0 & 1,0 \\
\hline $\begin{array}{l}\text { Умышленное причинение } \\
\text { тяжкого вреда здоровью }\end{array}$ & 1,80 & 1,80 & 1,7 & 1,60 & 1,5 & 1,2 & 1,3 & 1,1 & 1,1 \\
\hline Кража & 45,09 & 46,80 & 49,8 & 52,10 & 52,9 & 54,3 & 55,1 & 54,1 & 53,2 \\
\hline Грабеж & 18,60 & 18,20 & 17,5 & 17,05 & 13,9 & 16,1 & 17,1 & 17,0 & 16,5 \\
\hline Разбой & 4,50 & 2,30 & 3,6 & 3,50 & 1,7 & 2,1 & 2,0 & 1,9 & 1,2 \\
\hline Хулиганство & 21,40 & 20,30 & 22,8 & 31,00 & 35,3 & 46,9 & 45,9 & 44,2 & 43,4 \\
\hline $\begin{array}{l}\text { Преступления, связанные с } \\
\text { наркотиками и психотропными } \\
\text { веществами }\end{array}$ & 4,20 & 4,05 & 2,3 & 3,20 & 3,7 & 2,8 & 2,1 & 2,0 & 2,0 \\
\hline
\end{tabular}

\footnotetext{
* Составлена по данным ГИАЦ УВД по Иркутской области.
} 
Статистические закономерности преступности несовершеннолетних очевидны. Так, для нее традиционно характерна «узость» сферы преступных посягательств. Она состоит преимущественно из кражи, грабежа, разбойного нападения, хулиганства, умышленного причинения вреда здоровью, убийства, т. е. представлена статистически 10-14 видами преступных посягательств, которые свойственны преступному поведению несовершеннолетних. При этом удельный вес хулиганства имеет стабильную тенденцию к росту, и его удельный вес за последнее практически десятилетие вырос более чем в два раза.

Характерной особенностью динамики преступного поведения несовершеннолетних является и наблюдаемый в последние годы в структуре корыстной преступности рост числа преступлений, отличающихся сложностью механизма их совершения, в частности мошенничества. В то же время количество традиционных корыстно-насильственных преступлений, таких как разбойные нападения, а также преступлений, связанных с незаконным оборотом наркотиков, существенно сократилось.

Кроме того, если ранее официальная статистика отражала преобладание преступлений с корыстно-насильственной мотивацией, то в последние годы, в соответствии с ее данными, фиксируется некоторое перераспределение мотивационной сферы. В настоящее время все большее распространение среди подростков получают преступления, совершаемые по агрессивно-хулиганским мотивам, т. е. общественно опасные поступки, которые связаны со стремлением к удовлетворению потребности в насилии и жестокости, что становится доминирующим мотивом преступного поведения несовершеннолетних. Так, в 2010 г. в Иркутской области хулиганство было совершено каждым пятым несовершеннолетним, выявленным из числа лиц, совершивших преступления, а в 2016 г. - уже каждым вторым.

Фактические особенности преступного поведения несовершеннолетних, качественные, скрытые ее параметры, изучаемые специалистами, отражают неблагополучие в этой сорере, о чем свидетельствуют многочисленные исследования, в том числе регионального масштаба [1; 2]. И личность современного преступника, совершившего преступление в несовершеннолетнем возрасте, к сожалению, отражает общие тенденции неблагополучия общества [3; 4]. Портрет современного несовершеннолетнего преступника выглядит достаточно пла- чевно и позволяет заключить о преобладании в среде преступников категории наименее защищенных и социально уязвимых слоев подростков, среди которых школьники занимают существенную долю.

Современные практики предупредительного воздействия на различные формы отклоняющегося, в том числе общественно опасного поведения несовершеннолетних, как известно, отличаются малой эффективностью и являются активным индикатором кризиса всей системы борьбы с преступностью. Поиск инновационных подходов и форм предупреждения преступного поведения активно продолжается. Новые альтернативные механизмы предупреждения преступности несовершеннолетних востребованы наукой и практикой.

Программы, направленные на расширение устойчивого внедрения восстановительного подхода не только в сорере правосудия, но и в иных сорерах, затрагивающих права и интересы подростка, сегодня инициативно апробируются на практике. Восстановительные программы, как предусмотрено на нормативном уровне, используются в реагировании не только на преступное поведение несовершеннолетних, но и в более широком аспекте проблемных, конфрликтных ситуаций во взаимоотношениях подростков в их микросреде, и прежде всего в школе.

Возможность использования медиации иее технологий в школе вызывает необходимость определения ее места в криминологической плоскости, т. е. в системе мер предупредительного воздействия на преступное поведение. Сегодня институт медиации уже рассматривается наукой как перспективное средство предупреждения преступности и ее различных, в том числе наиболее опасных форм - рецидивной преступности, преступности пенитенциарной, преступности несовершеннолетних [5]. Криминологическая же значимость медиации предполагает определение, прежде всего, ее места в самом механизме предупредительного воздействия на преступность.

Рассматривая меры предупреждения преступности как целостную структуру, представляющую системную совокупность разнообразных мер, реализуемых многочисленными субъектами и направленными на ее причинный комплекс, важно определить в ней роль и функциональные свойства медиативных технологий в целом. Не менее важным является и определение места и значения медиации в воспитательной среде, где школа выступает мощным длительным фактором как криминогенного, так и анти- 
криминогенного свойства. Стратегически значимым является также уяснение потенциала применимости восстановительных программ на базе школы в отношении лиц, совершивших преступления, возможность их реализации в сложившихся нормативных, организационно-правовых, экономических, социально-психологических условиях как элемента вторичной (непосредственной) криминологической профилактики.

Следуя традиционной классификации предупредительных криминологических мер на основании базовых критериев, предполагающих их распределение по уровню предупредительного воздействия и по степени деформации личности, необходимо соотнести медиативные технологии с практикой раннего предупреждения преступного поведения.

Рассматривая раннюю профилактику как криминологическую меру, мы придаем ей значение комплексного механизма по созданию условий всесторонней социализации личности по благоприятному типу, где отсутствуют или сведены к минимуму негативные обстоятельства фрормирования деформаций ее психологии. Данный механизм - это факторы микросреды личности подростка, школьника в их разнообразии, различной степени интенсивности действия и противоречивости, во взаимосвязи непосредственно влияющие на личность. Школа как самостоятельный длительный институт прежде всего ранней социализации личности подростка выполняет серьезную роль в фрормировании личностных свойств. И сложности разрешения возникающих в системе школьной среды проблем и конфрликтов на добровольной конструктивной основе, отраженные сознанием подростка-участника, активно способствуют формированию взглядов, установок, интересов и других психологических механизмов, не отягощенных деформациями.

Признавая сложности психологического контакта в среде школа - подросток и школу как фрактор микросреды подростка, отражающий проблемы всего социума, индикатора этих проблем, следует признать и сложности адаптации механизма медиации в школьной среде, в которой роли педагога и медиатора, в желаемом варианте, должнь взаимосвязанно привести к урегулированию возникшего конфлликта. Виды конфликтов, существующих в школе, весьма разнообразны и находятся в плоскости как межличностных, так и внутриличностных отношений. Их регулирование, в случае отсутствия негативных последствий конфликта, предусмотренных уголовным законом, есть мера раннего предупреждения. Наличие деформаций сознания, повлекших возникновение этих конфликтов, не находит дальнейшей реализации в совершенном преступлении.

Ранняя, или допреступная, профрилактика является таковой в качестве сдерживающего элемента дальнейшего регрессивного механизма развития конфоликта. Неурегулированность же конфликта способствует укреплению деформаций как определенного стереотипа его разрешения по негативному типу.

Границы ранней профилактики при этом достаточно широки, поскольку профилактика любого негативного явления, не обладающего признаками противоправности, - это и ранняя профилактика преступного поведения. Конфрликтность различных сторон - непосредственных либо опосредованных участников образовательного процесса - криминология традиционно рассматривает в системе явлений, детерминирующих преступное поведение, т. е. механизма криминогенной причинности в их взаимосвязи и взаимозависимости.

Медиация в школе оценивается как комплекс мер по созданию безопасного пространства для обучающихся, их родителей и педагогов, по формированию основ осознанного позитивного общения между ними, по оказанию помощи в правильном ориентировании и реагировании в различных жизненных ситуациях, кроме того, медиация является механизмом ранней профилактики преступного поведения как комплекса мер упреждающего воздействия на его детерминацию. И для этого она изначально наделена такими критериями, как беспристрастность медиатора, равенство сторон - участников конфликта. При этом медиация является эффективным способом не только разрешения споров и конорликтов, но и предупреждения возникновения и развития последних $[6$, с. 166; 7]. В этой связи она полностью соответствует пониманию раннего предупреждения как сложного разнообразного комплекса мер упреждающего воздействия по нейтрализации либо блокированию криминогенных деформаций личности и по оздоровлению ее микросреды.

Блокирование или нейтрализация криминогенно значимых фракторов применением конструктивного подхода к разрешению школьного конфликта, предотвращение его эскалации - плоскость криминологических исследований медиативных технологий в школе. Примеров тому, когда конфликты в школе заканчиваются совершением преступлений различной мотивации и степени тяжести, к сожалению, большое количество. 
Создание и повсеместное внедрение службы школьной медиации может помочь не только в профилактике и коррекции девиантного поведения учащихся, но и в формировании благоприятного психологического климата, безопасного пространства образовательного учреждения. В этом аспекте роль медиативных технологий позволяет отнести их к системе раннего предупреждения преступности несовершеннолетних (школьников). Направленность медиации на создание здоровой, благоприятной среды в микросоциуме выполняет важную профрилактическую роль.

Не менее значимым является сегодня практическая реализация проблемы применения медиативных технологий к подросткам-школьникам, совершившим преступление. В этом контексте роль медиативных технологий осложняется в связи с возникновением отношений между преступником и потерпевшим как участниками уголовного правосудия и применения восстановительных программ, сочетающих в себе медиацию и техники восстановительной юстиции в рамках единой процедуры. Применение школьной медиации осложнено рядом обстоятельств, среди которых специалисты называют прежде всего правовую неопределенность статуса школьной медиации, в том числе с позиций уголовно-процессуального законодательства, специфику и неоднозначность определения предмета медиативных технологий в случае совершения преступления подростком, многие организационные недостатки их практического воплощения, отсутствие единой политики реализации положений нормативных основ о медиации в школе относительно круга участников программ восстановления, юридической природы и места школьной медиации в восстановительном правосудии и др. [8; 9].

В контексте криминологической проблематики важно определить критерии отнесения школьной медиации к непосредственному предупреждению преступного поведения несовершеннолетних школьников. С криминологических позиций учащийся школы, совершивший преступление и ставший участником процедуры школьной медиации, является носителем комплекса реализованных деформаций сознания, которые во взаимодействии с негативными факторами внешней среды выступили элементами механизма индивидуального преступного поведения. Нейтрализация последствий совершенного преступления - содержание профилактических мер, направленных на причины и усло- вия реализованного преступления с целью их коррекции и недопущения рецидива.

В этой связи школьная медиация как процедура заглаживания вреда, причиненного правонарушителем, решения вопросов компенсации негативных последствий правонарушения и предупреждения возможности их повтора - воздействие на причины и условия совершенного преступления. И в этом русле важным является предотвращение возможности превращения данной процедуры в формальный механизм.

Таким образом, вопросы эфрфективности школьной медиации напрямую определяют и потенциал данной разновидности мер непосредственного предупреждения преступного поведения несовершеннолетних.

Организационная основа реализации медиативных технологий в этом аспекте предполагает ее присутствие в образовательных учреждениях на постоянной основе, с закреплением локальными нормативными актами, представляющими механизм межведомственного взаимодействия. Служба школьной медиации - это служба, созданная в образовательной организации и состоящая из работников образовательной организации, учащихся и их родителей, прошедших необходимую подготовку и обучение основам метода школьной медиации и медиативного подхода. Вместе с этим важно выстроить механизм взаимодействия между комиссией по делам несовершеннолетних и защите их прав и службой школьной медиации как между специализированными ведомствами и специалистами. Территориальной площадкой может стать город Иркутск, те школы, где имеется необходимый нормативно-правовой ресурс, налажена система взаимодействия инспекторов комиссий по делам несовершеннолетних и представителей школы, которые обучены медиативным технологиям.

Процедура применения мер вторичной профрилактики должна реализовываться в момент, когда станет известно о фракте совершения подростком общественно опасного деяния. Представители комиссии по делам несовершеннолетних и защите их прав связываются со службой школьной медиации как нормативно регламентированной на сегодняшний день структурой. Медиаторы предлагают конфрликтующим сторонам, в частности виновному и потерпевшему, принять участие в процедуре примирения. Следует сразу оговориться, что в первую очередь внимание обращено на материалы общественно опасных деяний, по которым получено постановление об отказе в воз- 
буждении уголовного дела в отношении подростков, не достигших возраста уголовной ответственности. Думается, что также возможно применение медиативных технологий школьной медиации и к лицам, достигшим возраста уголовной ответственности, при условии, что совершенные подростками преступления небольшой либо средней тяжести и не направлены против личности.

Положительный опыт реализации такой процедуры в регионах России уже имеется. В качестве примера можно привести опыт применения процедуры медиации в Пермском крае, где с 2006 г. фрактически в каждой второй школе работает служба школьной медиации. В крае их насчитывается более 480. Программы примирения проводятся с несовершеннолетними, совершившими общественно опасное деяние, правонарушение, с обоюдного согласия конфликтующих сторон. Основная цель направлена на осознание тяжести содеянного и предотвращение совершения нового преступления. Так, по данным Пермского края, в 2011 г. медиаторами было отработано 922 случая, из них 373 закончились примирением сторон, 197 - без примирительной встречи [10].

Вместе с этим интересен опыт межведомственного взаимодействия комиссий по делам несовершеннолетних и защите их прав со школьными службами примирения по восстановлению правосудия в Волгоградской области. Отмечается, что модель взаимодействия комиссий по делам несовершеннолетних и защите их прав, при которой их представители сопровождают конфликтующие стороны весь период восстановительной работы и совместно со школьной службой примирения организуют восстановительную работу, является эфффективной моделью профилактики правонарушений несовершеннолетних [11]. Заслуживает внимание опыт работы службы школьной медиации и в Ярославской области [12; 13]. На первом этапе работы по созданию службы в образовательной организации была составлена дорожная карта, которая включала следующее: разработка положения о Службе школьной медиации МОУ СОШ № 13; создание буклетов для родителей и педагогов; проведение мониторинга среди родителей, учеников, педагогов. Вместе с этим были проведены открытые педагогические советы, образовательные программы для родителей «Причины возникновения конфрликтов», заседание круглого стола по теме «Медиативный подход в решении проблем профилактики правонарушений несовершеннолетних». Сотрудники считают, что создание службы школьной медиации может помочь не только в профилактике и коррекции девиантного поведения учащихся, но и в формировании благоприятного психологического климата, безопасного пространства образовательного учреждения.

Между тем следует отметить и скептицизм в отношении создания служб школьной медиации. Так, некоторые авторы полагают, что инициатива их создания «идет по указке сверху», и опасность заключается в том, что такая служба будет функционировать как фрормальная структура, фактически не реализующая ни механизм медиации, ни восстановительные процедуры. По этой же причине ее будут «саботировать» ученики, администрация школы, педагоги, родители [14].

Нельзя не учитывать и те многочисленные факторы организационного порядка, которые затрудняют реализацию субъектами профилактики преступного поведения несовершеннолетних их функций [15]. Инертность мышления не менее значимая в этом аспекте причина, мешающая развитию и внедрению медиации [16]. Однако среди аргументов в защиту данных восстановительных практик следует обозначить наличие успешного опыта самих практик, реализация которого создает благоприятную атмосферу для оценки и понимания преимуществ медиации всеми ее участниками [17; 18]. Более того, судейским сообществом в процессе формирования механизма концепции дружественного ребенку правосудия отмечается, что на стадии подготовки дела к судебному процессу следует шире использовать возможности медиативных технологий, поскольку именно медиаторы находят взаимоприемлемое решение, устраивающее участников конфликта, в отличие от суда, где в процессе судебного разбирательства выигрывает только одна сторона [16].

Положительный эфффект от реализации стратегии школьной медиации как постоянной распространенной восстановительной практики в общем механизме восстановительных программ способен приобрести серьезный антикриминогенный потенциал. Согласованные усилия и заинтересованность всех субъектов, реализующих процедуру школьной медиации, совершенствование надлежащей организационно-правовой основы этой деятельности позволили преодолеть формальный подход уже на начальном этапе ее воплощения. Лишь в таком случае школьную медиацию можно будет назвать эфффективной мерой ранней либо непосредственной профилактики преступного поведения несовершеннолетних. 


\section{СПИСОК ИСПОЛЬЗОВАННОЙ ЛИТЕРАТУРЫ}

1. Ережипалиев Д. И. Преступность несовершеннолетних на современном этапе развития российского общества / Д. И. Ережипалиев / / Всероссийский криминологический журнал. - 2017. - Т. 11, № 1. - С. 98108. — DOI: 10.17150/2500-4255.2017.11(1).98-108.

2. Немерюк Е. Е. География преступности несовершеннолетних (на примере Приволжского федерального округа) / Е. Е. Немерюк, А. Ю. Банников, Н. В. Маслова / / Географический вестник. - 2014. — № 2 (29). C. 26-33.

3. Судакова Т. М. Предупреждение преступности несовершеннолетних в сфере незаконного оборота наркотиков через призму реализации антинаркотической стратегии / Т. М. Судакова, М. А. Сутурин // Всероссийский криминологический журнал. - 2016. - Т. 10, № 3. - С. 499-510. - DOI: 10.17150/25004255.2016.10(3).499-510.

4. Корнакова С. В. Современные тенденции насильственных преступлений, совершаемых несовершеннолетними / С. В. Корнакова, С. А. Корягина / / Всероссийский криминологический журнал. - 2016. - Т. 10, № 1. - C. 148-155. - DOI: 10.17150/1996-7756.2016.10(1).148-155.

5. Яковлев В. В. Институт медиации в системе ресоциализации несовершеннолетних преступников / В. В. Яковлев, И. С. Чуб // Гуманитарные, социально-экономические и общественные науки. - 2016. № $11 .-$ C. 177-184.

6. Яковлева Ю. А. Восстановительная медиация в современной школе / Ю. А. Яковлева // Вестник ТОГИРРО (Тюменский областной государственный институт развития регионального образования). 2016. - № 1. - С. 231-233.

7. Петренко А. И. Проблемы службы школьной медиации и пути их решения в развитии воспитывающего потенциала образовательной среды школы / А. И. Петренко / / Конференциум АСОУ : сб. науч. тр. и материалов науч.-практ. конф. - М. : Акад. соц. упр., 2016. - Вып. 1. - С. 77-82.

8. Карнозова Л. М. Различение медиации в рамках восстановительного правосудия и медиации из сферы урегулирования частноправовых споров / Л. М. Карнозова / / Вестник восстановительной юстиции. - 2015. № 12. - C. 4-9.

9. Соловьева С. В. Школьная служба медиации как институт восстановительного правосудия / С. В. Соловьева, Е. В. Ершова // Вестник Нижегородского университета им. Н. И. Лобачевского. - 2014. — № 3 (2). C. 212-217.

10. Бербер Е. В. Опыт Пермского края по внедрению примирительных программ в работе с несовершеннолетними / Е. В. Бербер / / Медиация как культура согласия и ресурс развития регионов России : материалы науч.-практ. конф., 27-28 марта 2012 г. / сост. Т. И. Марголина, Л. А. Ясырева. - Пермь : Перм. гос. нац. исслед. ун-т, 2012. - С. 25-26.

11. Маловичко И. С. Развитие межведомственного взаимодействия комиссий по делам несовершеннолетних и защите их прав со школьными службами примирения (медиация) по реализации восстановительного правосудия в отношении детей в Волгоградской области / И. С. Маловичко, И. В. Чугунова / / Вестник восстановительной юстиции. - 2016. - № 13. - С. 23-31.

12. Потемина М. П. Медиация в школе, ее связь с ранней профилактикой предупреждения правонарушений в подростковой среде / М. П. Потемина, Н. Ф. Хухарева, А. Ю. Петрова / / Становление служб медиации в Ярославской области (из опыта работы образовательных организаций, учреждений социального обслуживания, территориальных комиссий по делам несовершеннолетних и защите их прав) / под ред. О. Л. Кашиной, И. Г. Назаровой, И. Е. Шишаковой. - Ярославль : Ин-т развития образования, 2015. C. $97-100$.

13. Гребенникова М.Н.Деятельность служб школьной медиации Воронежской области / М. Н. Гребенникова / / Вестник восстановительной юстиции. - 2016. - № 13. - С. 38-39.

14. Андреева О. И. К вопросу об организации службы школьной медиации (примирения) / О. И. Андреева // Психолого-социальная работа в современном обществе: проблемы и решения : материалы междунар. науч.-практ. конф. / под общ. ред. Ю. П. Платонова. - СПб. : С.-Петерб. гос. ин-т психологии и соц. работы, 2016. - C. 409-411.

15. Садовникова М. Н. Медиация и медиативные технологии в профессиональной деятельности сотрудников системы профилактики преступности несовершеннолетних (ч. 1) / М. Н. Садовникова // Сибирский юридический вестник. - 2013. - № 3. - С. 76-80.

16. Юферова М. А. К вопросу о перспективах внедрения медиации в образовательных организациях / М. А. Юферова, С. Б. Чернецова, И.В.Упениеце // Дополнительное профессиональное образование в условиях модернизации : материалы 9-й Всерос. науч.-практ. Интернет-конф. (с междунар. участием) / под науч. ред. М. В. Новикова. - Ярославль : Яросл. гос. пед. ун-т им. К. Д. Ушинского, 2017. C. 200-204.

17. Садовникова М. Н. Дружественное к ребенку правосудие и восстановительно-медиативные технологии : аналит. обзор науч.-практ. форумов / М. Н. Садовникова, Э. Л. Раднаева // Сибирский юридический вестник. - 2016. - № 1. - С. 92-99.

\section{REFERENCES}

1. Erezhipaliev D. I. Juvenile delinquency at the present stage of Russian society's development. Vserossiiskii kriminologicheskii zhurnal= Russian Journal of Criminology, 2017, vol. 11, no. 1, pp. 98-108. DOI: 10.17150/25004255.2017.11(1).98-108. (In Russian). 
2. Nemeryuk E. E., Bannikov A. Yu., Maslova N. V. Geography of the juvenile delinquency (case study of the Volga Federal District). Geograficheskii Vestnik = Geographical Bulletin, 2014, no. 2 (29), pp. 26-33. (In Russian).

3. Sudakova T. M., Suturin M. A. Prevention of juvenile crime in the sphere of illegal drug trade from the standpoint of anti-drug strategy's implementation. Vserossiiskii kriminologicheskii zhurnal = Russian Journal of Criminology, 2016, vol. 10, no. 3, pp. 499-510. DOI: 10.17150/2500-4255.2016.10(3).499510. (In Russian).

4. Kornakova S. V., Koryagina S. A. Modern trends of violent crimes committed by minors. Vserossiiskii kriminologicheskii zhurnal = Russian Journal of Criminology, 2016, vol. 10, no. 1, pp. 148-155. DOI: 10.17150/19967756.2016.10(1).148-155. (In Russian).

5. Yakovlev V. V., Chub I. S. Institute of Mediation in the System of Juvenile Delinquent Resocialization. Gumanitarnye, sotsial'no-ekonomicheskie $i$ obshchestvennye nauki = Humanities, Social-Economic and Social Sciences, 2016, no. 11, pp. 177-184. (In Russian).

6. Yakovleva Yu. A. Restorative mediation at modern school. Vestnik TOGIRRO (Tyumenskii oblastnoi gosudarstvennyi institut razvitiya regional' nogo obrazovaniya) = Bulletin of Tyumen Regional State Institute of Regional Education Development, 2016, no. 1, pp. 231-233. (In Russian).

7. Petrenko A. I. Challenges of School Mediation Service and Ways to Solve Them in Developing Educational Potential of School Environment. Konferentsium ASOU. Materialy nauchno-prakticheskikh konferentsii [SSA Konferentsium. Materials of Research Conference]. Moscow, Social Stewardship Academy Publ., 2016, iss. 1, pp. 77-82. (In Russian).

8. Karnozova L. M. Differentiating between Mediation within the Restorative Justice and Mediation in Settling Private-Law Disputes. Vestnik vosstanovitel' noi yustitsii = Restorative Justice Herald, 2015, no. 12, pp. 4-9. (In Russian).

9. Solov'eva S. V., Ershova E. V. School mediation service as an institution of restorative justice. Vestnik Nizhegorodskogo universiteta im. N. I. Lobachevskogo = Bulletin of the Nizhny Novgorod University N. I. Lobachevsky, 2014, no. 3 (2), pp. 212-217. (In Russian).

10. Berber E. V. Case Study of Perm Krai in Implementation of Conciliating Programs for Minors. In Margolina T. I., Yasyreva L. A. (eds). Mediatsiya kak kul'tura soglasiya i resurs razvitiya regionov Rossii. Materialy nauchno-prakticheskoi konferentsii, 27-28 marta, $2012 \mathrm{~g}$. [Mediation as Conciliation Culture and a Resource of Russian Region Development. Materials of Research Conference, March 27-28, 2012]. Perm State National Research University Publ., 2012, pp. 25-26. (In Russian).

11. Malovichko I. S., Chugunova I. V. Development of Interdepartmental Interaction between Commissions of Affairs of Minors and Protection of Their Rights and School Conciliation Services (Mediation) in Implementing Restorative Justice in Regard to Minors in Volgograd Oblast. Vestnik vosstanovitel' noi yustitsii = Restorative Justice Herald, 2016, no. 13, pp. 23-31. (In Russian).

12. Potemina M. P., Khukhareva N. F., Petrova A. Yu. School mediation, its relation to the early prevention of juvenile delinquency. In Kashina O. L., Nazarova I. G., Shishakova I. E. (eds). Stanovlenie sluzhb mediatsii $v$ Yaroslavskoi oblasti (iz opyta raboty obrazovatel'nykh organizatsii, uchrezhdenii sotsial'nogo obsluzhivaniya, territorial'nykh komissii po delam nesovershennoletnikh i zashchite ikh prav) [Development of Yaroslavl Oblast Mediation Services (based on the Experience of Educational Organizations, Social Service Establishments, Regional Commissions of Juvenile Affairs)]. Yaroslavl, School for Advanced Studies Publ., 2015, pp. 97-100. (In Russian).

13. Grebennikova M. N. Work of School Mediation Services in Voronezh Oblast. Vestnik vosstanovitel' noi yustitsii = Restorative Justice Herald, 2016, no. 13, pp. 38-39. (In Russian).

14. Andreeva O. I. Organization of School Mediation (Conciliation) Service Revisited. In Platonov Yu. P. (ed.). Psikhologo-sotsial' naya rabota v sovremennom obshchestve: problemy i resheniya. Materialy mezhdunarodnykh nauchno-prakticheskikh konferentsii [Psychological and welfare activities in the modern society: problems and their solutions. Materials of International Research Conferences]. Saint-Petersburg State Institute of Psychology and Social Work Publ., 2016, pp. 409-411. (In Russian).

15. Sadovnikova M. N. Mediation and mediation techniques in the professional activities of employees of the system for juvenile delinquency prevention. Pt. 1. Sibirskii yuridicheskii vestnik = Siberian Legal Bulletin, 2013, no. 3, pp. 76-80. (In Russian).

16. Yuferova M. A., Chernetsova S. B., Upenietse I. V. Prospects for Introduction of Mediation in Educational Establishments. In Novikov M. V. (ed.). Dopolnitel' noe professional'noe obrazovanie v usloviyakh modernizatsii. Materialy 9-i Vserossiiskoi nauchno-prakticheskoi Internet-konferentsii (s mezhdunarodnym uchastiem) [Further Vocational Education in the Modernization Context. Materials of the $9^{\text {th }}$ All-Russian Applied Research Online Conference (with International Participation)]. Yaroslavl State Pedagogical University named after K. D. Ushinsky Publ., 2017, pp. $200-204$. (In Russian).

17. Sadovnikova M. N., Radnaeva E. L. The child-friendly justice and technologies of mediation and restorative justice: the analytical review of scientific forums of Eastern Siberia. Sibirskii yuridicheskii vestnik = Siberian Legal Bulletin, 2016, no. 1, pp. 92-99. (In Russian).

\section{Информация об авторах}

Судакова Татьяна Михайловна - кандидат юридических наук, доцент, заведующий кафредрой теории государства и права и социально-правовых

\section{Authors}

Tatyana M. Sudakova - PhD in Law, Associate Professor, Head of the Department of Theory of State and Law and Socio-legal Disciplines, Baikal State 
дисциплин, Байкальский государственный университет, 664003, г. Иркутск, ул. Ленина, 11, e-mail: krime@mail.ru.

Корягина Светлана Анатольевна - кандидат юридических наук, доцент, кафедра уголовного права, криминологии и уголовного процесса, Байкальский государственный университет, 664003, г. Иркутск, ул. Ленина, 11, e-mail: koryagina.sveta@ yandex.ru.

\section{Для цитирования}

Судакова Т. М. Медиативные технологии в раннем и непосредственном предупреждении преступного поведения школьников / Т. М. Судакова, С. А. Корягина // Известия Байкальского государственного университета. - 2017. - Т. 27, № 3. - С. 425433. - DOI: $10.17150 / 2500-2759.2017 .27(3) .425-433$.
University, 11 Lenin St., 664003, Irkutsk, Russian Federation, e-mail: krime@mail.ru.

Svetlana A. Koryagina - PhD in Law, Associate Professor, Department of Criminal Law, Criminology and the Criminal Process, Baikal State University, 11 Lenin St., 664003, Irkutsk, Russian Federation, e-mail: koryagina.sveta@yandex.ru.

\section{For Citation}

Sudakova T. M., Koryagina S. A. Mediation Technologies in Early and Direct Prevention of Criminal Behavior of Schoolchildren. Izvestiya Baykal'skogo gosudarstvennogo universiteta $=$ Bulletin of Baikal State University, 2017, vol. 27, no. 3, pp. 425-433. DOI: 10.17150/2500-2759.2017.27(3).425-433. (In Russian). 